\title{
No Fault Found: The Search for the Root Cause
}




\title{
Other SAE books of interest
}

\author{
Integrated Vehicle Health Management: \\ The Technology \\ Edited by Ian K. Jennions \\ (Product Code: R-429) \\ Integrated Vehicle Health Management: \\ Implementation and Lessons Learned \\ Edited by Ian K. Jennions \\ (Product Code: R-438) \\ Counterfeit Electronic Parts \\ and Their Impact on Supply Chains \\ By Kirsten M. Koepsel \\ (Product Code: T-130)
}

For more information or to order a book, contact:

SAE INTERNATIONAL

400 Commonwealth Drive

Warrendale, PA 15096

Phone: +1.877 .606 .7323 (U.S. and Canada only) or +1.724 .776 .4970 (outside U.S. and Canada)

Fax: +1.724 .776 .0790$

Email: CustomerService@sae.org

Website: books.sae.org 


\section{No Fault Found: The Search for the Root Cause \\ By Samir Khan, Paul Phillips, \\ Christopher J. Hockley, and lan K. Jennions}

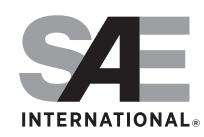

Warrendale, Pennsylvania, USA 


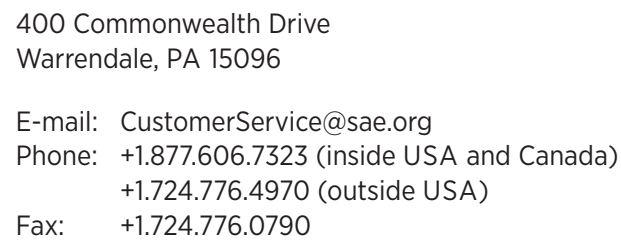

Copyright () 2015 SAE International. All rights reserved.

No part of this publication may be reproduced, stored in a retrieval system, distributed, or transmitted, in any form or by any means without the prior written permission of SAE International. For permission and licensing requests, contact SAE Permissions, 400 Commonwealth Drive, Warrendale, PA 15096-0001 USA; email: copyright@sae.org; phone: +1.724 .772 .4028 ; fax: +1.724 .772 .9765 .

\title{
SAE Order Number R-441
} http://dx.doi.org/10.4271/r-441

\author{
Library of Congress Cataloging-in-Publication Data \\ Kahn, Samir. \\ No fault found : the search for the root cause / by Samir Kahn, Paul Phillips, \\ Christopher J. Hockley, and Ian K. Jennions.$$
\text { pages } \mathrm{cm}
$$ \\ Includes bibliographical references. \\ ISBN 978-0-7680-8122-0 \\ 1. Fault location (Engineering) 2. Systems engineering. I. Title. \\ TA169.6.K34 2015 \\ 620'.00452--dc23 \\ 2015018194
}

Information contained in this work has been obtained by SAE International from sources believed to be reliable. However, neither SAE International nor its authors guarantee the accuracy or completeness of any information published herein and neither SAE International nor its authors shall be responsible for any errors, omissions, or damages arising out of use of this information. This work is published with the understanding that SAE International and its authors are supplying information, but are not attempting to render engineering or other professional services. If such services are required, the assistance of an appropriate professional should be sought.
ISBN-Print 978-0-7680-8122-0
ISBN-PDF 978-0-7680-8227-2
ISBN-epub 978-0-7680-8229-6
ISBN-prc 978-0-7680-8228-9

To purchase bulk quantities, please contact:

SAE Customer Service

E-mail: CustomerService@sae.org

Phone: +1.877.606.7323 (inside USA and Canada)

+1.724 .776 .4970 (outside USA)

Fax: $\quad+1.724 .776 .0790$

Visit the SAE International Bookstore at BOOKS.SAE.ORG 


\section{Table of Contents}

Acknowledgments ............................................................................ix

Chapter 1: Introduction ..................................................................... 1

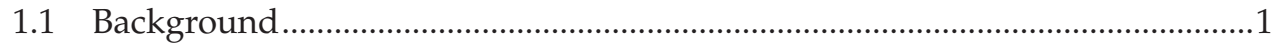

1.1.1 Maintenance and NFF-Historical Perspective ......................................

1.1.2 The Growth of NFF within Aerospace ..................................................

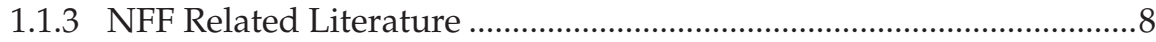

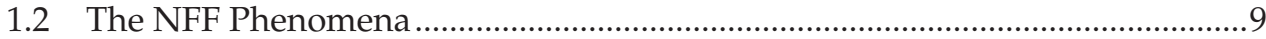

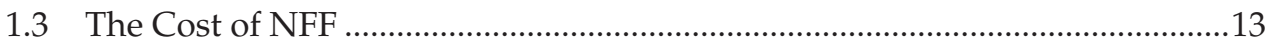

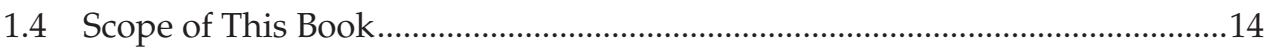

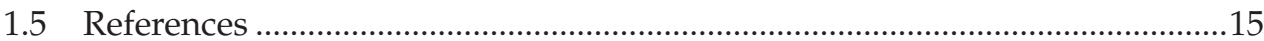

Chapter 2: Basics and Clarification of Terminology..................... 17

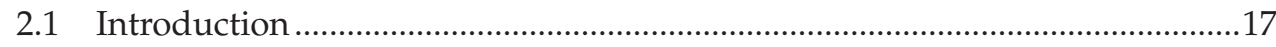

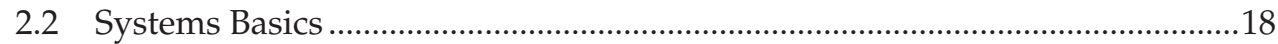

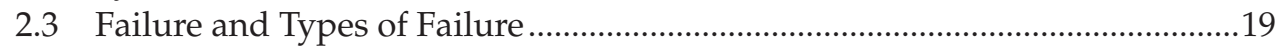

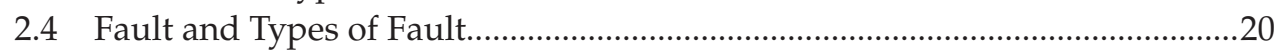

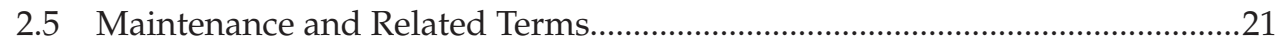

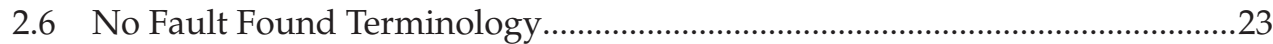

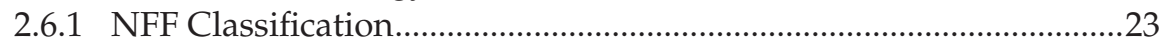

2.6.2 Case Study-The Impact of Inconsistent Terminology ........................30

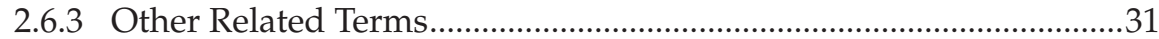

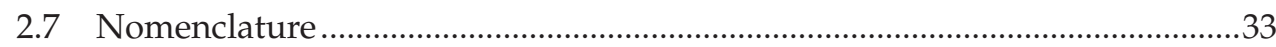

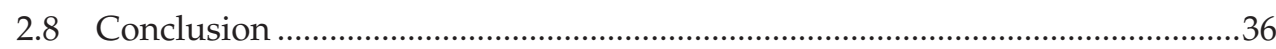

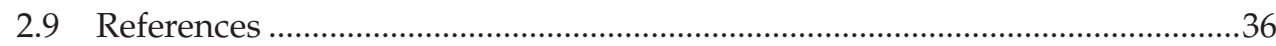

Chapter 3: The Human Influence .................................................... 39

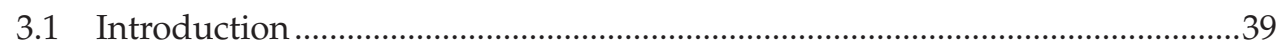

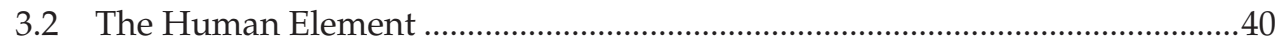

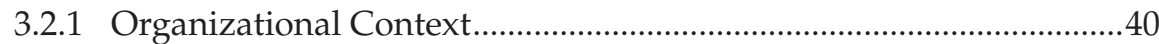

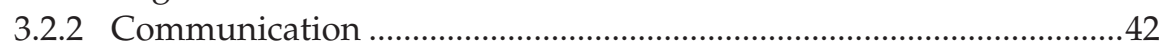

3.2.3 Human Factors Impacting NFF ...........................................................4

3.3 The Maintenance Engineer and System Interactions ......................................46

3.3.1 Typical Maintenance Processes in Civil Aircraft ................................46

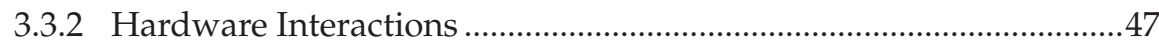

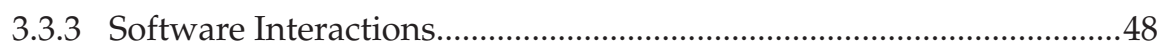

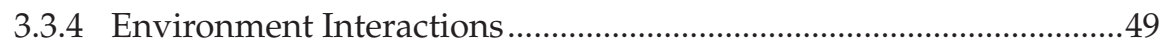

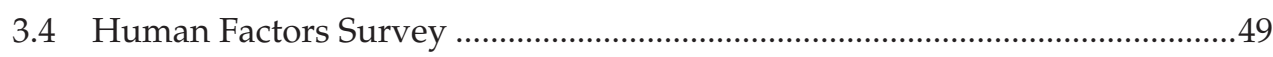

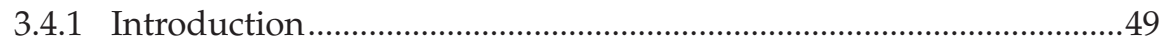

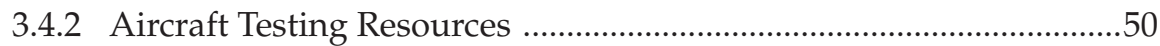

3.4.3 Aircraft Maintenance Manuals ..............................................................52

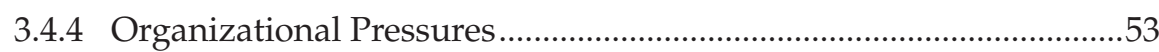

3.4.5 Maintenance Engineer: Competence and Training.............................55 


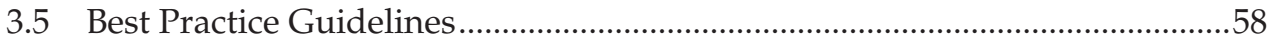

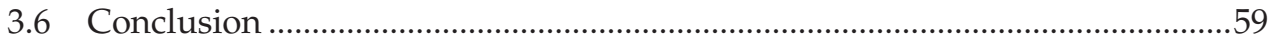

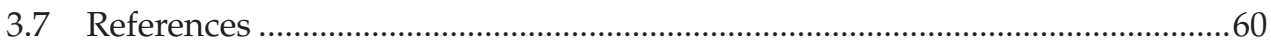

Chapter 4: Availability in Context .................................................61

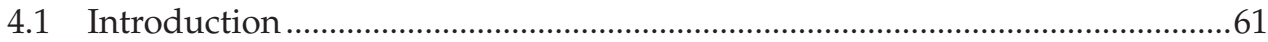

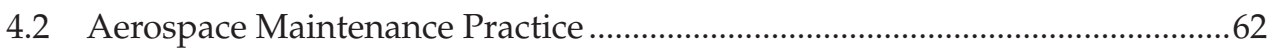

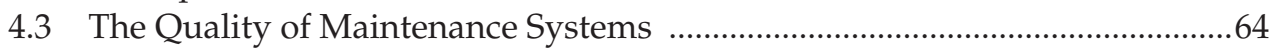

4.4 Design for Maintenance and System Effectiveness ............................................66

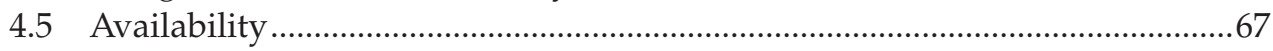

4.5.1 The Multiple Facets of Availability .................................................67

4.5.2 Design Requirements for RAM .......................................................

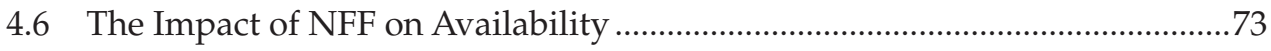

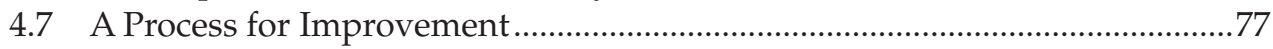

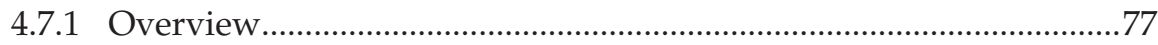

4.7.2 A Methodology for Monitoring NFF In-Service ................................8 80

4.7.3 Unit Removal Datasheets ..................................................................... 80

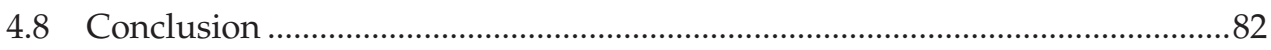

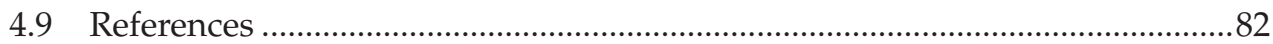

Chapter 5: Safety Perceptions.................................................. 85

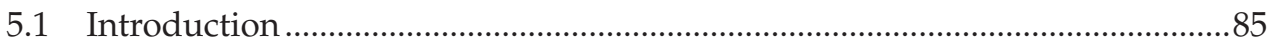

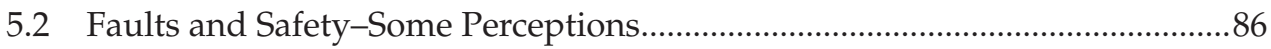

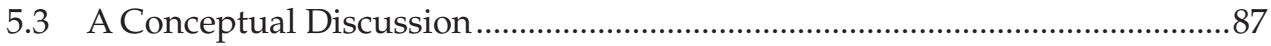

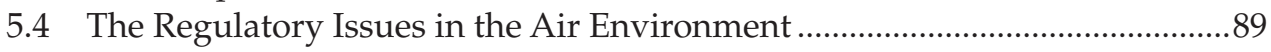

5.5 Faults and the Link with Maintenance Errors ...................................................91

5.5.1 The Maintenance Contribution..........................................................91

5.5.2 Operational Pressure ........................................................................ 92

5.5.3 The Human Factors Contribution ........................................................93

5.5.4 Diagnostic Maintenance Success .......................................................96

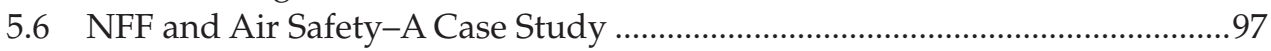

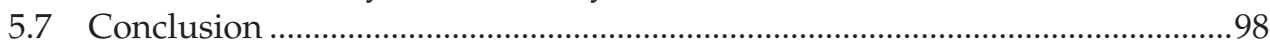

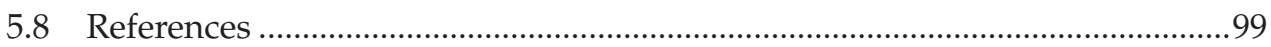

Chapter 6: Operating Policies for Management Guidance ............ 101

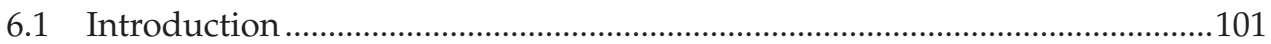

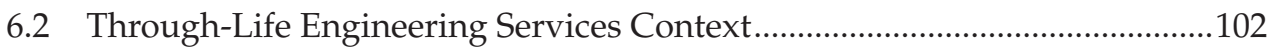

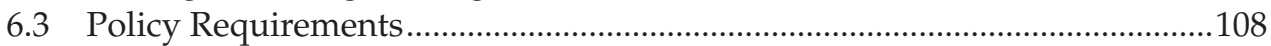

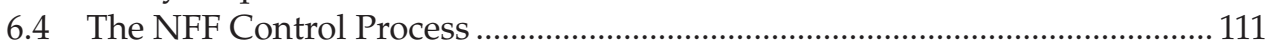

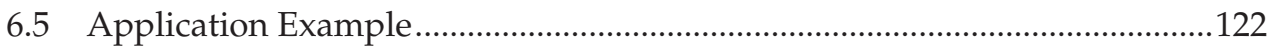

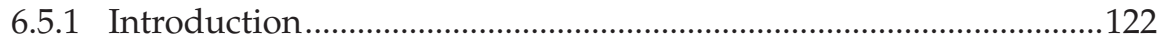

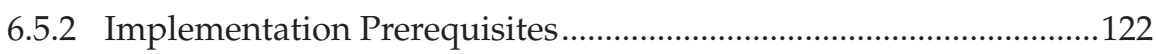

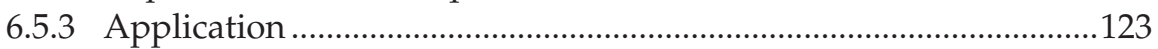

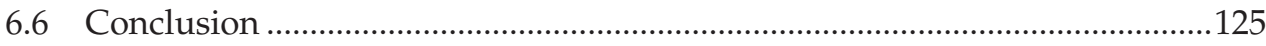

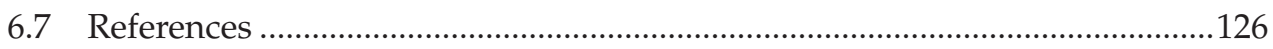


Chapter 7: A Benchmark Tool for NFF

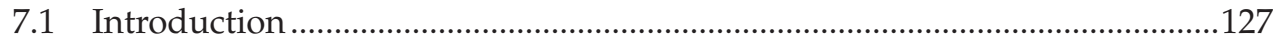

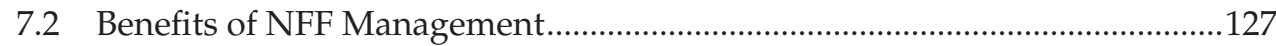

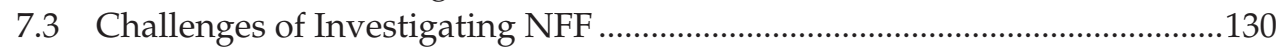

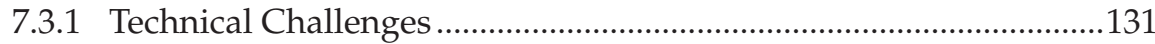

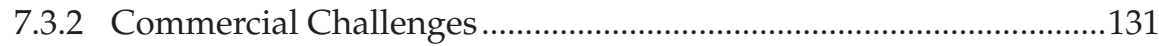

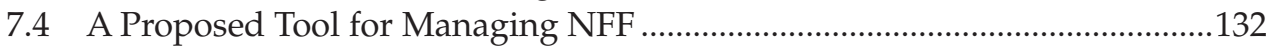

7.4.1 The Benchmark Tool.....................................................................132

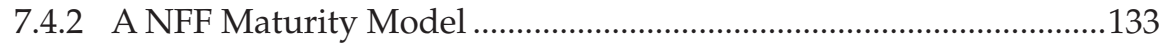

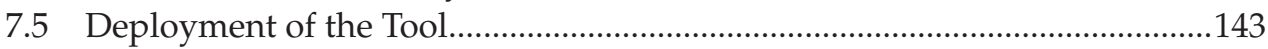

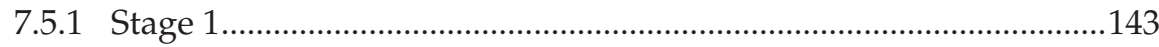

7.5.2 Stage 2

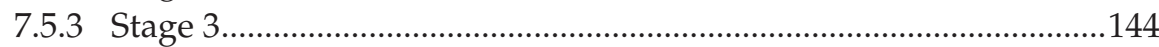

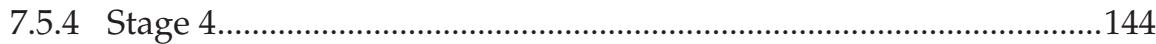

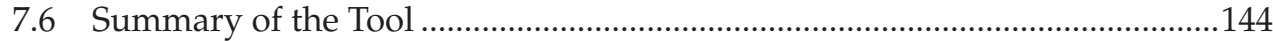

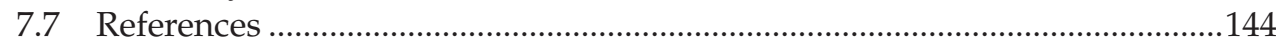

Chapter 8: Improving System and Diagnostic Design ................. 145

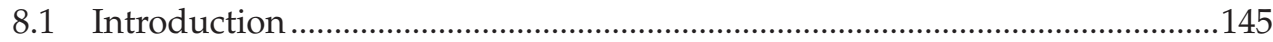

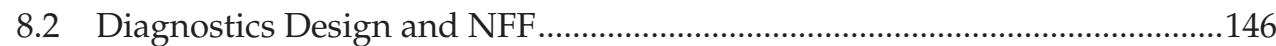

8.2.1 In-Service Feedback Activities ..........................................................147

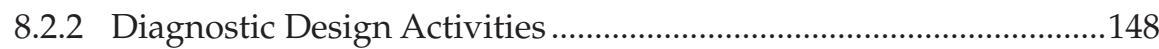

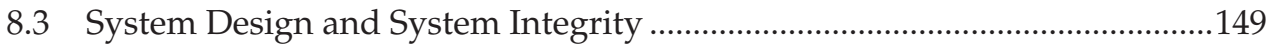

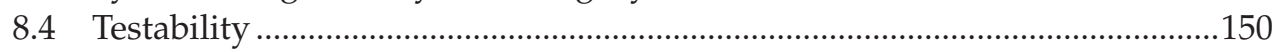

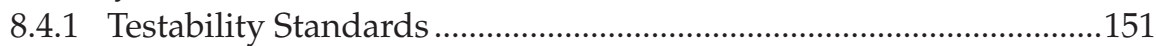

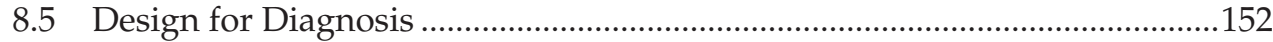

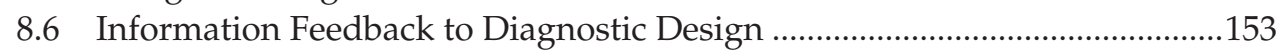

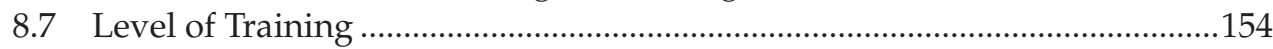

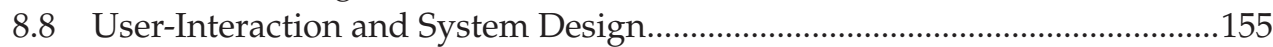

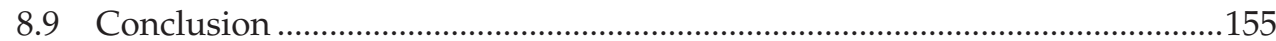

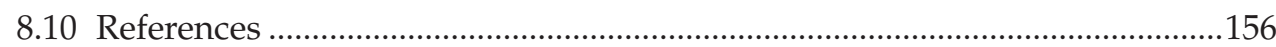


Chapter 9: Technologies for Reducing No Fault Found................ 159

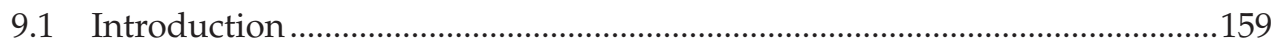

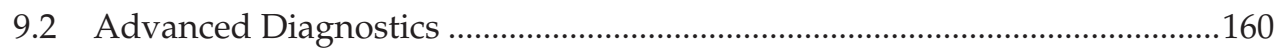

9.2.1 Health and Usage Monitoring of Electrical Systems .......................160

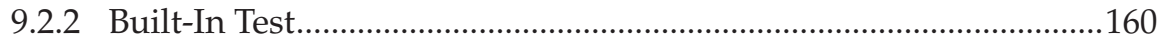

9.2.3 Monitoring and Reasoning of Failure Precursors .............................163

9.2.4 Monitoring Life-Cycle Loads ...........................................................165

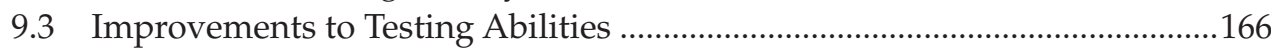

9.3.1 Testability as a Design Variable ........................................................166

9.3.2 Functional and Integrity Testing ....................................................167

9.3.3 Testing Under Environmental Conditions ........................................169

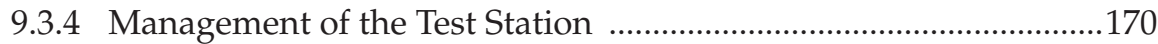

9.3.5 Tracking Spare Part Units ................................................................. 171

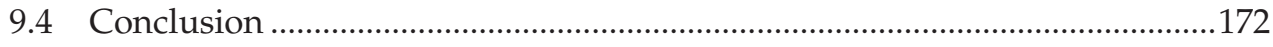

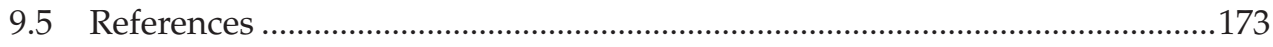

Chapter 10: Summary and Ideas for Future Work...................... 175

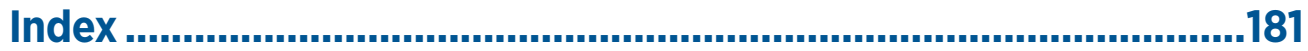

About the Authors .........................................................................191 


\section{Acknowledgments}

The authors wish to acknowledge the support and opportunity provided by the EPSRC Centre for Innovative Manufacturing in Through-Life Engineering Services in the preparation of this book. The Centre was set up by the EPSRC in June 2011 as a partnership between Cranfield and Durham Universities with 5 main projects, research into NFF being one of those. Initial research established that there was very little knowledge and information available in the public domain about NFF. What information that did exist seemed to be in specialist publications or only readily available to limited groups or industries. An early aspiration of the project therefore was to redress this deficiency with a book that would provide a foundation in the subject for engineers and managers alike. The research and knowledge gained during the NFF project within the Centre has provided both the material, and certainly the inspiration, for this book.

We are most grateful to the Centre Director, Professor Raj Roy for his encouragement and to the SAE for the opportunity. In particular we would like to thank Monica Nogueira at SAE who has helped us achieve our aspirations. We trust that you the reader will find this a useful book in your efforts to understand and hopefully reduce the occurrence of NFF in your area of responsibility. 